\title{
Short Notes on Marine Polycladids (Platyhelminthes, Turbellaria, Polycladida) from Karachi Coast
}

\author{
Quddusi B. Kazmi \\ Marine Reference Collection and Resource Centre, University of Karachi, Pakistan
}

Abstract: Ten new records of marine polycladid worms are subject of the present notes from Pakistan. Each species is photographed and discussed briefly.

\section{INTRODUCTION}

The Polycladida represents a highly diverse clade of free-living marine turbellarian flatworms. They are known from the littoral to the sub littoral zone. Although not related to molluscs, they are often mistaken for sea slugs because of their brilliant colour patterns. There is little known about the biodiversity of polycladid flatworms from the Indian Ocean. In Pakistan, studies on polycladids have remained neglected, first report was by Kazmi (1996), then Fatima and Barkati (1999) as Stylochoplanapallida reported Emprosthopharynxpallida (Quatrefage,1845) and latelyKazmi and Naushaba (2013) listed 4 unidentified species or only identified to genus level, of these , their unspecified genus Pseudocerosis now identified as belonging to Pseudocerossusanae Newman and Anderson ,1997, an undetermined pseudocertid is now named as Tytthosoceroslizardensis Newman and Cannon,1996 and another undetermined genus is given as Cestoplanarubrocinta (Grube, 1840) ,more species are added here;all are briefly described here and are recorded for the first time from Pakistan. Some still awaiting identification are also mentioned. It clearly shows that these animals are recognizable by their colour patterns with only slight variations. Hyman (1959) and Prudhoe (1985) maintained that colour patterns provided sufficient information to recognize species; my identification is also based on colour pattern viewing that within the family Pseudocerotidae, species have been recognized solely on the basis of their colour patterns (Newman and Cannon, 1994, 1995a, b, 1998; Sreeraj and Raghunathan, 2013). Reliability of the use these colour patterns for species diagnosis has been confirmed with molecular data (Goggin and Newman, 1996).However, for a proper identification of these groups with histological sectioning is also required not by only looking at the colour pattern (Hassan Rahimianpers.comm).

\section{RESUltS AND DisCUSSION}

Following are taxonomic descriptions and remarks on the species I investigated. The present study reports ten new records of polycladids to Pakistani marine fauna.

Family Pseudocerotidae Lang, $1884 \mathrm{f}$

\section{PSeudoceros Susanae NeWman AND ANDERSON, 1997 (Figs.1-3)}

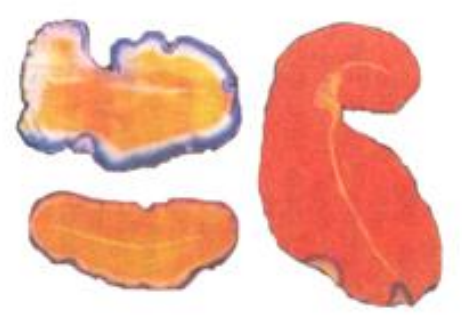

Figs1-3. Pseudocerossusainae, different shades

\subsection{Material}

Several specimens of different sizes under stones in intertidal region dated19 April, 1995, New Pacha; 18 January, 1996, Manora 


\subsection{Colour Pattern}

Back ground yellow-orange, violet and dark royal blue bands towards the margin .Medially orange with a longitudinal white stripe which bifurcates the orange area, starting anterior to the cerebral eyespot and ending anterior to the posterior margin. Ventrally orange with light blue margin. Smaller specimen without marginal bands. The colour varied in two localities.

\subsection{Description}

Body elongate-oval with shallow marginal ruffles. Pseudotentacles simple folds. Cerebral eyespot horseshoe-shaped with about 40 eyes. Dorsal pseudotentacular eyes along the anterior margin in three to four rows. Ventral pseudotentacular eyes in two clusters. Pharynx with complex folds, mouth central. Single male pore posterior to the pharynx, female pore posterior to male pore. Sucker small, located at mid body. (After Newman and Anderson, 1997)

\subsection{Remarks}

There appears to be some variation in colour pattern mentioned for the specimens from Indonesia and Maldives by Newman and Anderson (1997). Pakistani specimens also show variation in background colour and marginal bands and quite resemble that described for Pseudoceros cf. susanaeby Apte and Pitale (2011) from Lakshadweep. This variation may be a geographical variation or it might turn out to be a new species.Pseudocerossusanaehas been illustrated in several popular books but has been consistently misidentified as $P$. dimidiatus(Newman and Anderson, 1997)

\subsection{Habitat and Distribution}

Pseudocerossusanaeis one of the most common pseudocerotid flatworms observed in the intertidal region in Karachi. Also recorded from Komodo, Indonesia, Mahe, Seychelles and Maldives.

\section{TytThosoceros LiZARDENSis NeWMAN AND CANNON, 1996 (FigS.4-5)}
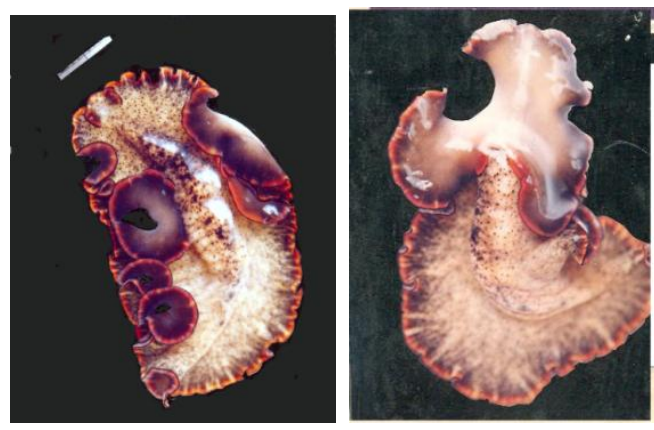

Figs4-5. Tytthosoceroslizardensis

\subsection{Material}

One specimen, intertidal region, Bulleji, collected 9 March, 1996

\subsection{Background Colour}

Light brown with cream mottling composed of dots forming loose transverse streaks medially and laterally, marginal black band, interrupted with short white transverse streaks of dots at rim, margin narrow, bright orange band. Pseudotentacles with white tips and cream mottling between. Ventrally purplish brown toward the margin, orange submargin and black rim.

\subsection{Description}

Body elongate and oval, extremely soft and delicate, raised medially with deeply crenulated marginal ruffles, tapering slightly posteriorly. Pseudotentacles relatively small, formed from the anterior margin, ear-like, held erect. Cerebral eye spot horseshoe shaped with about 60-100 eyes in clear oval area.

\subsection{Habitat and Distribution}

Tytthosoceroslizardensis has been reported from reef crests and slopes of Queensland and the Great Barrier Reef (Newman and Cannon 1996), and also mentioned in a multimedia CD on flatworm diversity (Newman and Cannon ,2005) as being known from Indonesia, the Philippines, and South Africa.Khalili et al (2009) reported the species from the Persian Gulf and Dixitet al (2015) from India. 


\section{ThYSANOZOON? BROCCHII (RISSO, 1818) (FIGS.6-8)}

\subsection{Material}

Several specimens among seaweeds, collected 6 November, 1993, Buleji; 25 November, 1995, Pacha

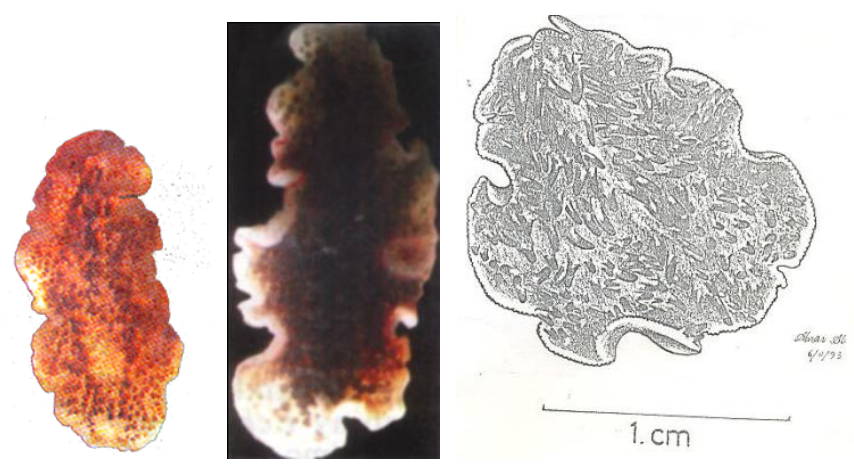

Figs6-8. Thysanozoon? brocchii

\subsection{Remarks}

The specimens in two different shades, most likely are Thysanozoonbrocchii, which is considered to be cosmopolitan .Upper surface of the animals is covered with short finger-like papillae, this is a hallmark of the genus Thysanozoon. Khalili et al (2009) described an undetermined species of the genus from the Persian Gulf and opined that it "might well turn out to represent a new species". There are similar probabilities for Pakistani specimens.

\section{PSEUdobiceros UndeTermined SPECIES (Fig.9)}

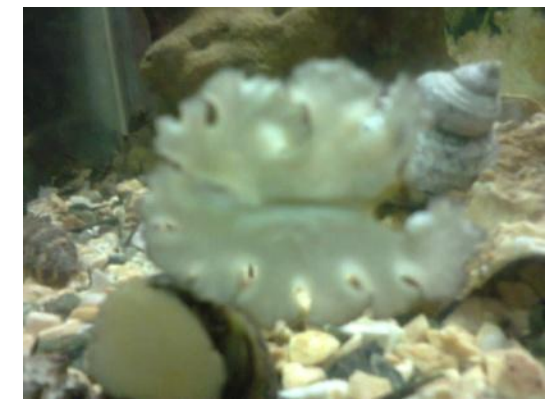

Fig9. Pseudobicerossp, ventral view, on aquarium wall

\subsection{Material}

Two specimens, in MRC aquarium, one damaged, photographed, collected November, 2015

\subsection{Remark}

In aquarium the exact colour could not be determined but possibly dorsally buff, mottled dark grey/mauve, concentrated on middorsal ridge into a streak and on margin as band. The underside is uniformly pale with a pale mauve thin marginal band .The body edge is highly ruffled . My best guess was that they should be placed in the family Pseudocerotidae Lang, 1884

Family Cestoplanidae Lang, 1884

\section{Cestoplana? Rubrocinta (Grube, 1840) Lang, 1884(Figs.10-13)}

\subsection{Material}

23 December, 1996, Sandspit

\subsection{Colour Pattern}

Reddish-yellow with four longitudinal red bands. two in the middle, one near each lateral edge; cephalic regions and the ventral surface whitish. The median band in the present material is made of twin lines thus differing from typical pattern of the species The dorsal coloration with the twin reddish-brown longitudinal bands running the entire length of the body are also distinctive for a nemertean species Tetrastemmaquadrilineatum. 


\subsection{Description}

With an elongate, ribbon-like body bearing an adhesive depression at the posterior end. Anterior region with numerous eyes .No tentacles. mouth situated posteriorly.

\subsection{Habitat and Distribution}

Under stones between the tidemark English Channel, Cape Verde Isle, Mediterranean, Italy, East Africa ,ShriLanka, Australia and Japan.

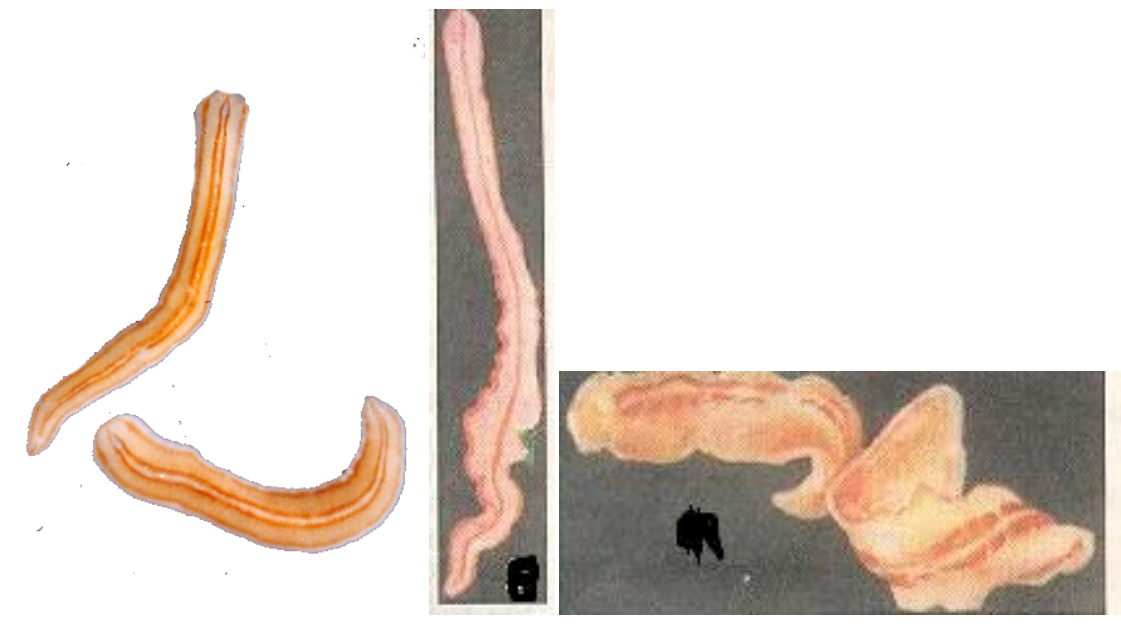

Figs10-13. Cestoplana? Rubrocinta Family StylochidaeStimpson, 1857

\section{STylochus SPP. (Figs. 14-15)}

\subsection{Material}

Several specimens, 15 January, 1996, Bulleji

\subsection{Description}

Body oval in shape, greatly flattened, $2 \mathrm{~cm}$ in length, rather fleshy flatworms either uniformly pinkish or grayish beige, with a central streak; smooth body surface with no obvious pseudo tentacles.

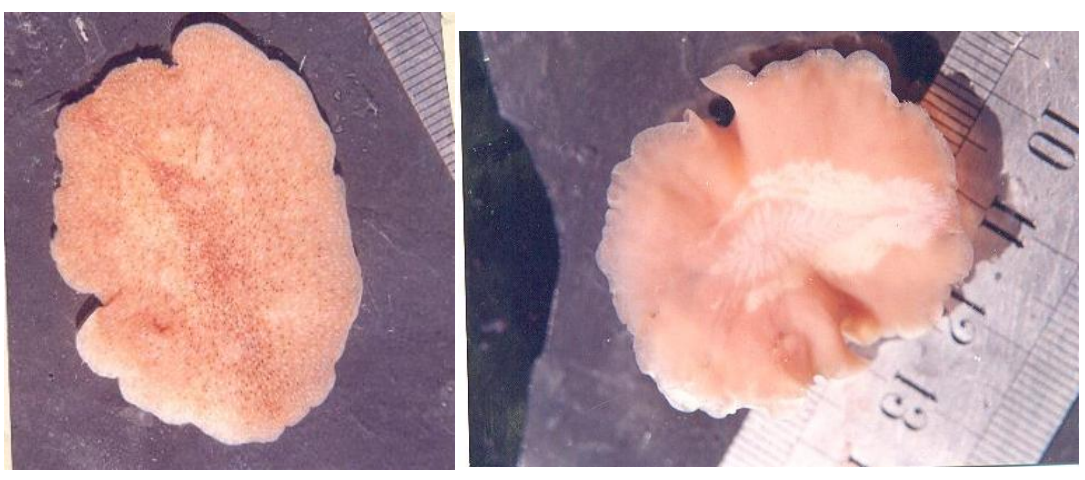

Figs14-15. Stylochus sp., dorsal and ventral view

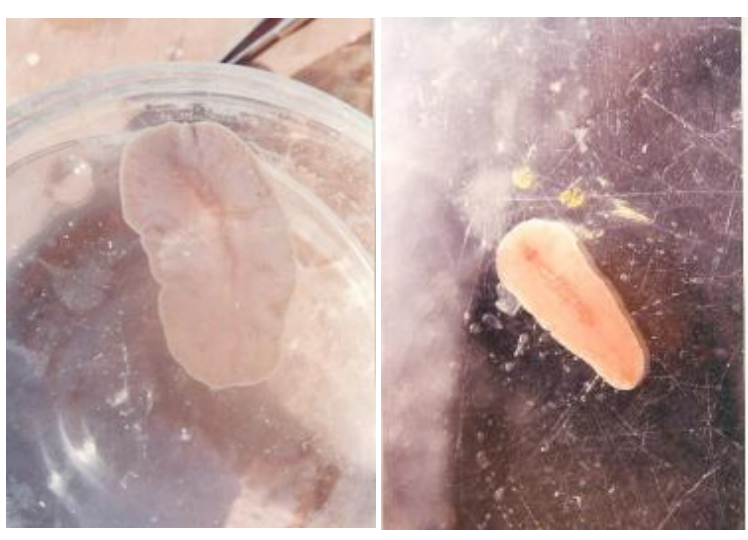

Figs16-17. StylochusspFamily Notoplanidae Marcus and Marcus, 1966 
9. Notoplana? Alcinoi (SCHMidT, 1862) (Fig. 18)

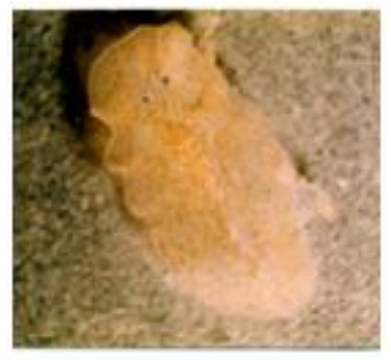

Fig18. Notoplana? alcinoi

\subsection{Material}

One specimen, under stones in intertidal region

\subsection{Description}

With a delicate, wedged body, tenticular eyes arranged in two circular clusters

\section{Notoplana SP (Figs.19-20)}

\subsection{Description}

Body flat; margin thin and undulated; shape leaf-like, but changeable; about one inch long and one half of an inch wide; color pale orange, veined with a lighter shade.

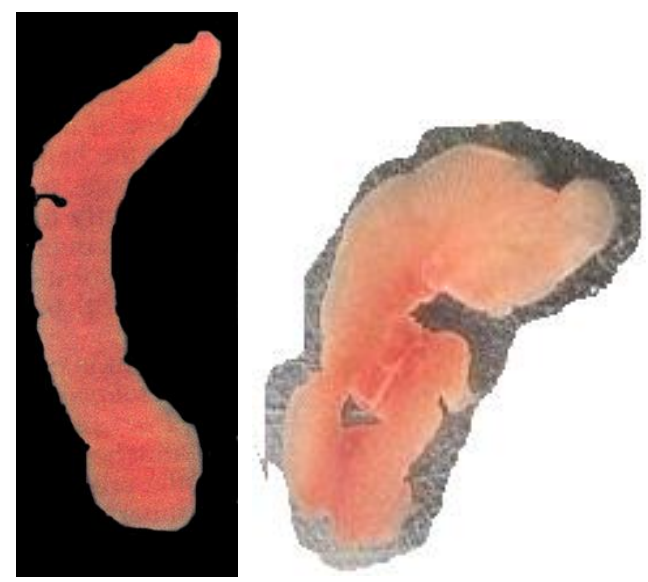

Figs19-20. Notoplanasp

\section{ACKNOWLEDGMENTS}

I am grateful to Dr.ZahraKhalili of Department of Animal Science, University of Tehran and Dr. Mehrez Gammoudi of Unité de Recherché, Campus Universitaire El Manar Tunis, and Tunisia for their kind help in identification. Dr. Hassan Rahimian of Faculty of Biological Sciences, College of Sciences, and University of Tehran is also thanked for comments on ms.

\section{REFERENCES}

Pâté, D.and R. D. Pitale, 2011. New records of polyclad flatworms (Platyhelminthes: Turbellaria) from coral reefs of Lakshadweep Island, India. Jour. Bombay Nat. Hist. Soc., 108(2): 109-113.

Dixit, S., C. Sivaperuman and C. Raghunathan, 2015.Three new records of polyclad flatworms from India. Marine Biodiversity Records / Volume 8/, e29 (4 pages)

Goggin, G.L. and L.J. Newman. 1996. Species discrimination in pseudocerotid flatworms (Platyhelminthes, Polycladida) using ribosomal DNA. Journal of Helminthology 70: 123-126

Hyman, L.H. 1959. A further study of Micronesian polyclad flatworms. Proc. United States Nat. Mus., 108: 543-597.

Kazmi Q.B., 1996. Polyclad worms.MRC Newsletter5 (2):1

Kazmi Q.B. and R.Naushaba, 2013. Checklist of marine worms reported from Pakistani marine waters. Pakistan Jour. Nematology, 2013, Vol. 31 (2), 187-280 
Khalili ,Z., Rahimian H., P. Jamile,2009.First record of the family Pseudocerotidae (Platyhelminthes, Polycladida, Cotylea) from the Persian Gulf, Iran.Zookeys 31:39-51

Newman,L.J. and R. C. Anderson,1997.A new species and new records of Pseudoceros (Turbellaria, Polycladida) from the Maldives J. South Asian nat. Hist., 2, ( 2): 247-256; 7 figs.

Newman, L.J. and L.R.G. Cannon. 1994. Pseudoceros and Pseudobiceros (Polycladida, Pseudocerotidae) from Eastern Australia and Papua New Guinea. Memoirs of the Queensland Museum 37: 205-266.

Newman, L.J. and L.R.G. Cannon. 1995a. Color variation in Pseudoceros (Platyhelminthes, Polycladida). The Raffles Bulletin of Zoology 43: 435-446.

Newman, L.J. and L.R.G. Cannon. 1995b. The importance of the fixation of color, pattern and form in tropical Pseudocerotidae (Platyhelminthes, Polycladida). Hydrobiologia 305: 141-143.

Newman, L.J. and L.R.G. Cannon. 1998. New Pseudoceros (Platyhelminthes, Polycladida, Pseudocerotidae) from the Indo-Pacific. Raffles Bulletin of Zoology. 46(2): 293-323.

Prudhoe, S. 1985. A Monograph on Polyclad Turbellaria. Oxford Univ. Press, Oxford. 2

$59 \mathrm{pp}$

Sreeraj, C. R. C. and Raghunathan, 2013.Pseudocerotid polyclads (Platyhelminthes, Turbellaria, Polycladida) from Andaman and Nicobar Islands, India 